\title{
Cervical cancer in lquitos, Peru: local realities to guide prevention planning
}

\author{
Câncer cérvico-uterino em lquitos, Peru: \\ realidade local como guia \\ para planejamento da prevenção
}

Jennifer L. Hunter ${ }^{1}$

\footnotetext{
1 School of Nursing in Kansas City, University of Missouri, Kansas City, USA.

Correspondence Jennifer L. Hunter School of Nursing Health Sciences Building, University of Missouri. 2220 Holmes Street, Kansas City, Missouri 64108-2676,USA. hunterj@umkc.edu
}

\begin{abstract}
Cervical cancer is a major public health problem in Latin America, and in much of the underdeveloped world. This issue has not historically been addressed as a health priority, but in recent years is receiving increased attention and funding. This ethnographic study on the experience of cervical cancer was conducted in Iquitos, Peru, between August 1998 and May 1999. Research methodologies included: (1) observation and household interviews to obtain background knowledge about the region, medical systems, and local cultural understanding of illness; (2) cancer experience interviews; and (3) case studies of women in various stages of cervical cancer or diagnosis. Findings are presented related to local knowledge and experience of Pap smears and cervical cancer and the ineffectiveness of a recently initiated cervical cancer screening program. The findings guide recommendations for interventions in the region in relation to: (1) needed changes in health education, (2) screening frequency and age, (3) sites for screening and treatment, (4) type and availability of treatment, (5) payment issues, (6) documentation of care, and (7) the potential of herbal remedies.
\end{abstract}

Cervix Neoplasm; Women's Health; Population Surveillance

\section{Introduction}

At 42 years old, Emelda was dying. She knew it. She was in bed now, weak, in pain, unable to walk. She could no longer eat, and was horribly emaciated. Her neighbors and family spoke with her of getting well, but they knew that she was dying. They had seen it before, too many times.

Two and a half years earlier, Emelda had experienced persistent vaginal discharge and bleeding between her periods. She asked her neighbor, Rosa, for advice, and Rosa had told her she should go to the posta (health post) and get a Papanicolou test. Emelda had heard of the test from other women who had been having descensos (vaginal discharge) like she was having. Some even said you should have the test every year to see if you had cancer. Emelda had been hesitant, but Rosa said that she would go with her, so Emelda consented. She had the three soles (approximately one US dollar) to pay for the visit and the Papanicolou was free, but she worried that she did not have enough money to buy medicines if the doctor prescribed them. Maybe she could buy just one or two pills.

Still, Emelda had been terrified. She had heard that they put an apparatus that looked like a big spoon inside you, and she was afraid it would hurt. Worse, she had heard that sometimes they took something out of you with that 
apparatus. Mostly, she was terrified of having cancer. She tried hard to block out memories that haunted her.

Emelda had watched her aunt die of this women's cancer. Her aunt had been plump and healthy, but in the course of just a few years she had lost weight and become so very thin. She could not eat. Emelda's mother had said it was because her intestines had grown together and food could not get through anymore. Emelda remembered her aunt crying in pain - burning pain. She remembered her mother cleansing away the watery, bloody discharge that kept pouring out of her. Emelda's family said that her aunt dried up when all that fluid ran out, and turned yellow with anemia when she ran out of blood. Finally, no more fluid came out. She could not urinate. The pain was unbearable. And then she died.

Emelda's test had not hurt much, but the doctor looked concerned when he told her to come back in three weeks to get her results. When she returned, they told her the results were not back yet, to return again in another month. The next month, the same thing happened again. When she returned a third time, the doctor overheard her asking for the results at the desk. "What has taken you so long to return?" he scolded her. She explained that this was the third time she had come, and that they still had no results. He took the inch-thick pile of results and looked through them. "Here it is", he said. "They have spelled your name wrong. The results are inconclusive", he told Emelda. "You may have cancer and you may not. Come, I want to examine you again." During the examination, the doctor said, "There is an area on your cervix that is not normal. We need a biopsy to see if it is cancer." He referred Emelda to a gynecologist at the hospital.

Emelda was so frightened, she left the clinic hardly able to think. She did not speak to anyone, and she could not sleep all night. Her friend Rosa paid her ride to the hospital very early the next morning. Emelda waited in line for a long time, but she hardly noticed. The next thing she knew she was with the gynecologist, handing him the little note that the doctor in the posta had given her. He did a biopsy. It hurt a lot. He took three carnecitas (little pieces of meat) and put them in a little bottle of fluid. He gave her the bottle and told her to take it to the pathologist in Iquitos to be analyzed. It would cost 70 soles for each little piece, he said. If the cancer was early, he told her, she could have surgery here in Iquitos. If it was advanced, she would have to go to Lima for treatment.

She took the bottle and walked out. She just walked and cried. Cancer! Seventy soles for each piece! Surgery! Lima! She had no money! Not even to pay for the analysis of one little piece! She became angry at her husband for not saving more money, and for wasting it on aguardiente (rum). He only made 150, maybe 200 soles a month, even if he found work every day, and the children had to eat. In anger, fear and desperation, she threw the little bottle in the river. "It is probably nothing," she told herself. Less than three years later, she lay dying.

Emelda's story is real, but she is not just one woman. Rather, her story represents a compilation of several women's narratives, gathered in Iquitos, Peru. Tragically, these experiences are not rare. Cervical cancer kills more than 230,000 women each year worldwide. At least $80 \%$ of the deaths occur in developing countries, disproportionately affecting the world's poorest, most vulnerable women. Cervical cancer is a major public health problem in Latin America, and Peru is among the countries with the highest incidence and mortality rates 1 . Efforts have been made to implement cervical cancer screening in poor countries for more than 30 years, but in most cases they have not significantly impacted the incidence or mortality from this cancer 2,3,4,5.

Since the mid-1990s, the topic of cervical cancer has surfaced as an increasing priority in the discourse of the World Health Organization (WHO). Director-General Dr. Gro Harlem Brundtland has discussed the importance of cervical cancer within the scope of non-communicable diseases 6 and as a priority within an expanded scope of reproductive health 7 . In an address to the International Agency for Research on Cancer (IARC), she noted the disturbing incongruity between what is known about the prevention and treatment of cervical cancer, the prevalence of cervical cancer in poor areas of the world, and the lack of translation of this knowledge into effective programs internationally 6 .

In 1999, the Bill \& Melinda Gates Foundation awarded a $\$ 50$ million grant to the Alliance for Cervical Cancer Prevention (ACCP), a group of five international organizations with a shared goal of working to prevent cervical cancer in developing countries 7. The five participating agencies are the Pan American Health Organization (PAHO), Program for Appropriate Tech- 
nology in Health (PATH), IARC, JHPIEGO, a nonprofit organization affiliated with Johns Hopkins University, and EngenderHealth. The Alliance has looked to qualitative studies, addressing women's concerns and barriers to cervical cancer screening in Mexico, Venezuela, Ecuador, El Salvador, and Peru, to guide their work. This study extends the available qualitative information available for Peru, addressing the city of Iquitos and surrounding villages in the department of Loreto.

In the present study, the researcher participated in the community life of Iquitos for nine months; explored surrounding river villages, hospitals, clinics, and traditional healing practices; and entered into homes and intimate cancer experiences of women and their families. Through these experiences, the researcher gained a close look at the realities surrounding cervical cancer in this region and insights into the inadequacies of a cervical cancer screening program recently introduced by the resourcechallenged Ministry of Health.

\section{The setting}

Iquitos is located in northeast Peru, and is the capital of the country's largest department, or State, Loreto. It is the largest city in the Peruvian Amazon, a city in the midst of jungle, with a population of well over 400,000 . It is the site where the many tributaries flowing down from the Andes merge together to become the great Amazon River. The tributaries are the circulatory system of Amazonia, carrying food, people, animals, medicines, goods, and information that are lifeblood for Iquitos and its surrounding river communities.

Once an important rubber boom capital, Iquitos is now a quiet town of small commercial businesses, logging, agriculture, oil, and tourism. Only a small number of people prosper from the current enterprises, and the majority of the population is very poor. Many are unemployed or get very occasional work. Nonprofessional jobs, at the time of the research, paid between 200 and 300 soles per month (US\$60 to 100). Professional jobs paid somewhat more. A teacher earned 350 to 800 soles (US\$105 to 260 ), a nurse, 600 soles (US\$180), and a physician, US\$600 per month. Like the poor in many world regions, home remedies and medicinal plants were used for prevention and treatment of illness, biomedical health care was purchased only if the illness continued to worsen, and spending time and money for preventive services was rare.
Like other urban areas of Peru, Iquitos has a fairly well developed central core and an impoverished periphery. Downtown Iquitos has paved streets, nice buildings that protect from the environment, electricity (most of the time), and running water (some of the time). As one moves outward from the center, houses become more rustic, constructed of thin wood and thatched roofs, and roads become dirt. Most residents in the periphery do not have piped water, but carry water from delivery trucks or from nearby rivers or lakes, where bathing, laundry, and dishwashing are also done. Trash removal is far from adequate, and outhouses straddle small stream beds which are dry half of the year. Communities close to the rivers which border Iquitos are quite similar to the rustic rural river villages throughout Loreto. In Amazonia, as in Andean regions, rural villages are poor, and travel to distant urban centers is difficult.

\section{Methodology}

The study was ethnographic in nature, conducted from August 1998 to May 1999. Ethnography allows a researcher to be present over time and to observe everyday life, the way practices are built out of shared knowledge, the meaning people find in their lives, and the constraints and pressures to which those lives are subject 9,10. Two types of ethnography were used, as described by Agar 9. "Narrative" ethnography elicited people's stories of their cancer experiences, and "encyclopedic" ethnography provided information about the local culture to serve as a background for narrative analysis. Background exploration included: (1) the city of Iquitos and surrounding river villages, (2) national and regional morbidity and mortality statistics, (3) Iquitos hospitals, health posts, and records accessed with the permission of the Ministry of Health, (4) practices of local vegetalistas and healers, (5) Lima's National Cancer Institute or Instituto Nacional de Enfermedades Neoplásicas (INEN), Peru's only cancer hospital, and (6) household illness interviews.

The extensive household illness interviews were conducted in a port community, where housing structures, occupations, the market area, and interaction of urban and rural lives made it representative of much of the poorer population of Iquitos. Interview questions were designed to gather background information regarding the larger cultural understanding of and responses to common illnesses. Thirty of the approximately 150 households in the neigh- 
borhood were randomly selected and interviewed. Questions about the family's knowledge of and experience with cancer were included at the end of the interview.

In addition to the collection of over 60 cancer narratives, eight women in some stage of cervical cancer or diagnosis were followed as case studies. Although these cases were gathered as a purposive versus a probability sample, the group represented low, mid-range, and high socioeconomic status and educational levels, urban and rural settings, and various stages of screening and treatment. Two of these women had received positive Pap tests and were seeking follow-up; a third woman had surgery in Lima during the study; and a fourth had radiation therapy in Lima six years previously and was now suffering treatment-related problems. The four remaining women had widespread disease, and all died in their homes during the month of February, 1999. The author's background, both as a nurse with experience in hospice and palliative care and as an anthropologist, provided a combination of skills well suited to the intimate and intense nature of this research.

\section{Under-representation of cervical cancer in local statistics}

There are two cancer registries in Peru, one in Trujillo and one in the Lima greater metropolitan area, which offer fairly reliable disease statistics. In Trujillo, the incidence of cervical cancer is 115.4 per 100,000 women between the ages of 35 and 64, and the cumulative risk for cervical cancer in Lima is 1 in 35 women 1,8. There are no cervical cancer morbidity statistics for Loreto. Cancer cases are not counted. Mortality statistics are gathered by Peru's Ministry of Health, but do not reflect the same cervical cancer significance as do the registries. On the contrary, they indicate that very few deaths occur from cervical cancer. Mortality statistics published for Loreto document six deaths from cervical cancer in 1990, 12 in 1991, 10 in 1994, 17 in 1995, and 22 in 1996. 11,12,13 These statistics, like any from underdeveloped regions, must be closely scrutinized.

There is considerable evidence to indicate that cervical cancer is significantly under- represented in the above-cited regional data. One factor is the underreporting of deaths common in underdeveloped regions. In a 1998 report, the Pan-American Health Organization estimated that for 1992, underreporting of deaths in Peru at the national level was $50.8 \%$, and
$79.9 \%$ in Loreto 4 . Recording a death in Iquitos costs money, and is mainly done to obtain permission to bury in the public cemeteries. It is rarely done by the very poor or for infant deaths. Another factor is inaccurate documentation of cause of death. Since there is little to nothing that can be done locally for women with cervical cancer, they are often unknown to the medical system until a family member brings a death certificate for physician signature and describes the symptoms of the deceased. Cause of death is based on this description.

As an example, of nine women in the present study known to have died of cervical cancer, only five had death registration; causes of death for two were registered as cancer of the cervix, one as uterine cancer, one as stomach cancer, and one as bronchial asthma. The misclassification of cervical cancer as stomach cancer in this region could be the result of the local reference to cervical cancer as "cancer of the vientre". Locally, the Spanish-language term vientre refers to female organs, but outside of the local vernacular, it refers to belly, lower abdomen, or bowels, and could easily be transcribed in mortality statistics to stomach or bowel cancer. Terminal complications of cervical cancer such as severe malnutrition, emaciation, anemia, abdominal pain, and intestinal or urinary tract obstruction could lead to misclassification of cervical cancer as a cancer of the digestive or urinary system or as nutritional deficiency 4. Terminal cancer can also involve the respiratory system, as was the case in the woman whose cause of death was recorded as bronchial asthma. Moreover, PAHO 4 estimates that the proportion of deaths attributed to ill-defined signs, symptoms, and conditions was $30.6 \%$ overall, and $69.8 \%$ in less developed regions.

\section{Local cancer knowledge}

Local cancer statistics on cervical cancer are countered by local voices. Local voices in Iquitos vividly reflect current and long-term significance of cervical cancer among its women. Consider some comments from household interviews:

"Yes, my mother-in-law died of (cervical) cancer, a friend, and also a neighbor. I have a sister that had cancer. It is an experience that has had a great impact on me."

"Both of our mothers (hers and her husband's) died of cancer. We also have a neighbor with cancer. My mother started to lose weight and had nausea, and as time went on she start- 
ed to have vaginal bleeding. She started bleeding a lot, and then she had swelling. They wanted her to go to Lima, but we didn't have the money."

"I have the experience of one of my sisters. She died of cancer. I know many women who have died of cancer. They had bleeding. Day by day, they dried up. They get very, very skinny and yellow. That's how my sister died, very bony."

"I have heard of cancer for a long time, because my grandparents told me. My mother died of cancer. It is a very old illness. You know, it comes from long ago."

Local narratives revealed an intimate knowledge of the realities of untreated cervical cancer that few in advanced nations have witnessed.

"One day, my mother was washing clothes from 6:00 to 1:00 ...Then she felt something - she looked and she saw blood. And she asked, 'Why am I having my period?' She changed her clothes, and went to the living room, and then there was more blood. She started to have a big hemorrhage. She was three days at home with hemorrhaging. Three days later, in the night, she called us. She was desperate. We were sleeping. And then we turned on the lights, and we saw that her bed was full of blood. It was as if someone had killed a pig. We took her to the hospital and admitted her. As time went on, she continued to bleed. Then she started to have a discharge with a bad odor. My mother had been very fat; she was a well-fed woman. Better said, she was drying up, with the water running out. The water she was losing made her very thin."

"The malignant tumors destroy you. They finish you off inside. A woman died on Grau Street, and we went there. She couldn't urinate or defecate. She asked if we would clean her with an enema. Here there are many fresh plants, and she wanted us to put them in an enema. We had intended to do it, but it burned her inside, and she cried, "It burns, it burns." She was closed on both sides, the anus and the urinary tract. There was no entrance of the vagina or the anus. The Señora died, but so destroyed. The tumor burst and emptied. Eight days later, she died."

The regional director of epidemiology concurred that cervical cancer was more significant than Peru's statistics revealed, and that it was not a new disease in Iquitos:

"We are in an epidemiological transition in this country, but I personally think that there has always been cervical cancer. Still, the morbidity is ill-defined, like the diagnoses and the mortality. It is well-defined that tumors are definitely increasing as a cause of mortality, but I think that there has always been cancer. I believe that the problem of statistics is disguising the true dimension of cancer. Compared to the written data, cervical cancer probably happens much more frequently than we think."

A gynecologist at the Regional Hospital had seen numerous cases of cervical cancer. He had developed an interest in the disease, and had tried to follow cases from 1991 and 1992.

"In that one year we found 44 cases of cancer in the neck of the uterus. Most were in an advanced state. Those in advanced stages are sent to Lima for radiation therapy at INEN, the National Cancer Institute. However, patients without resources can't go. There are very few cases that go to Lima:2\%.There are no economic resources for them. We don't treat those in advanced states. These patients, they stay, and they die:advanced cancer. There are cases of persons from 21 to 71 years old. This is tragic for the patient. In the statistics that we have done for 22 to 25 years, the majority of cancer presents here from 30 years and up. I was doing a follow-up of these patients, for example, of one 22-yearold. She died in 1993 with metastasis. There are other patients, one 35 years old that I visited last year with stage $3 B$, advanced cancer, who was still alive. I was doing that follow-up, but I stopped, because it was so difficult to find them; or they had changed houses. But it would be very important."

This gynecologist said that in recent years, he had seen 50 to 55 cases of cervical cancer per year. He is only 1 of 16 gynecologists in two hospitals. If each of these physicians saw the same number of cases, it would amount to over 800 per year among those women who go to the doctor. An emergency room physician at the local hospital also saw many cases of cervical cancer. He estimated that $5 \%$ of the emergency room visits at the Iquitos Hospital were from women with vaginal hemorrhage, bowel and urinary tract obstruction, and severe pain from advanced cervical cancer. Based on the number of emergency room visits to that hospital in 1998, 5\% represented 1800 visits at one hospital alone. The above-mentioned gynecologist estimated that 1 in 10 women in Iquitos/Loreto would get cervical cancer in their lifetime. Given the world cancer patterns for underdeveloped areas and that the cumulative risk for cervical cancer in Lima had decreased in previous years to 1 in 35 women, a 1 in 10 cumulative risk for the much less developed region of Iquitos was not an outrageous estimate. Regardless, most women are diagnosed too late for treatment, and if only $2 \%$ can afford to go to $\mathrm{Li}$ ma for hope of a cure, the cervical cancer mortality in the region is nearly equal to its incidence. This number is assuredly more than the 6 to 22 per year recorded in regional statistics. 


\section{Cervical cancer screening in lquitos}

In 1997, Peru's Ministry of Health initiated a cytological cervical cancer screening program in Loreto within the Family Planning Program. The program was based in Iquitos and was active in the Iquitos public hospital, the Regional Hospital, and in 45 community health posts. Pap smears taken in the various clinical locations were sent in bulk twice a month to a pathology laboratory in Lima which was said to provide services at a much lower rate than the pathologist in Iquitos. The results were said to return in approximately 15 days, although this was seldom the case. Pap smears were free for women between 30 and 49 years of age.

Most of the women who did Pap smears were from the city of Iquitos, rather than from peripheral regions. In 1997, according to the coordinator of the program, 8,938 total tests were taken at the hospitals, health posts, and during occasional community health campaigns. Of those, 242 tests were read as positive. These included high and low-grade lesions (CIN I, II, III, and carcinoma in situ), and eight invasive cancers. In 1998, 9,260 total tests were done. There were 240 positive tests in this group, including 165 low-grade lesions (CIN I and II), 55 high-grade lesions (CIN III and carcinoma in situ), and 20 invasive cancers. These numbers must also be tempered by the facts that specimens were poorly stored and were often several weeks old before being sent to Lima, external quality assurance was highly unlikely in either laboratory, and false negative rates are known to be high 14,15,16,17,18.

\section{Problems with Pap smears}

\section{Diagnostic versus preventative use}

Although some residents spoke of illness prevention, limited family funds were rarely spent on health until problems were very evident. Pap smears in Iquitos were primarily used to aid in diagnosis of gynecologic problems, rather than for preventative screening. Even two years after initiation of the new program, no local narratives were heard by the researcher that described a Pap smear as a test to check for asymptomatic, precancerous lesions. The local rationale for getting a Pap smear was "to see if you had cancer".

The diagnostic versus preventative use of Pap smears has been further augmented by the World Health Organization's approach of "downstaging." Over the years, WHO has advocated downstaging as a more realistic approach in developing countries. Its goal was to increase the number of cervical cancers identified in early versus late stages for a higher chance of cure $19,20,21,22$. The approach emphasized women's empowerment through education about early warning signs of cervical cancer (such as intermenstrual, post-coital, or postmenopausal bleeding, or foul vaginal discharge) and early diagnosis 22 . This is a very different educational approach than teaching women the importance of regular screening for precancerous lesions which are detectable before they are symptomatic. A significant disadvantage to the symptom approach is that in developing countries, treatment facilities even for Stages I and IIA cancers are limited and invasive cancers at any stage are complex, expensive to treat, and require hospitalization 23. In Iquitos, small, precancerous lesions or tiny localized cancers can be treated relatively inexpensively with cauterization or excision. However, when cervical cancer has progressed enough to be symptomatic, cure is highly unlikely in this setting.

\section{The "Lone Pap" versus a comprehensive} prevention program

Although seemingly obvious, the fact that any screening test alone does not prevent or cure cervical cancer must be stressed. An effective cytological cervical cancer screening program consists of a spectrum of components which include obtaining the Pap smear, preparation of the sample, laboratory interpretation of the sample, appropriate follow-up of abnormalities, and access to proper treatment 24,25.

In Iquitos, conization and cauterization are the available treatments for pre-invasive cervical lesions. Hysterectomy is available for persistent lesions or invasive cancer limited to the uterus. Only 1 of the 16 gynecologists performed conizations, but all of them were able to perform hysterectomies. At the time of the study, cauterization could only be done in private physicians' offices because the cauterization machine at the Regional Hospital had been broken for a year and a half. The cost of a cauterization by a private physician was 150 to 200 soles (50 to 70 US dollars), close to the monthly income of many informal workers. A conization cost 200 to 300 soles (70 to 100 US dollars), and a hysterectomy approximately 1,000 soles (over 300 US dollars). Radiation treatment for more invasive cancers could only be obtained in Lima.

Whatever treatment was recommended, few women followed through with the recom- 
mendations. "The women agree to the treatment, but then they disappear and do not return." The gynecologist who does conizations said that he had done only five in the last year. Surgery records from March 1998 through January 1999 listed six hysterectomies, two for high-grade cervical lesions and one for invasive cancer. Most women cannot afford these treatments and there is no assistance with financial planning. Some eventually find or save the money, but when they return for the treatment, it is too late. Finally, those who accept available local treatment are often lost within a fragmented, inefficient system and rarely have sufficient information or communication patterns to find their way through.

Thus, though treatment options exist, the system, the economy, and the culture of communication and problem-solving render these options inaccessible to most poor women. A similar situation has been found by the ACCP in San Martin, where a baseline assessment documented that only $25 \%$ of women with abnormal Pap smears received follow-up diagnosis and treatment 26. As Tulinius et al. 27 (p. 689) pointed out long ago, "It goes almost without saying that screening for cancer is not worth much if efficient therapy is not available." Without efficient therapy, "screening would hardly be justifiable".

\section{The screening instrument}

Despite the demonstrated effectiveness of Pap smears in decreasing the incidence of cervical cancer in developed countries, the test has drawn concerns in recent years regarding its accuracy. The main concern has been the high number of false negative tests related to the instrument's low sensitivity. Based on a recent meta-study done by the Agency for Health Care Policy and Research 14. researchers and clinicians were advised to consider the sensitivity of Pap smear screening close to $50 \%$. False negative rates ranging from 11 to $54 \%$ have been documented in Latin America 15,16,17,18. Laboratory interpretation of cervical cytology is complex and influenced by many variables. Quality control is scant to nonexistent in underdeveloped regions, and training of lab technicians is rarely standardized. With developing countries having only a small percent of the global resources for cancer control, one cannot overlook the real cost of the Western model for cervical screening and the infrastructure necessary to make it effective. The cost of screening programs in the United States in 1996 was nearly $\$ 6$ billion annually 28 .
Proper specimen preparation is also essential for quality. In observations in Iquitos, the basic smear technique appeared adequate, although patients seldom were instructed not to douche, wash the vagina, or have intercourse for 24 hours prior to a Pap test. The patient's name and the date were written on a scrap of paper and folded around the prepared slide, which was rubber-banded into a group of slides waiting in the tropical heat until enough were collected to warrant postage to Lima for analysis. In one case, a slide was over two months old before it was sent to Lima, though said to be good for only 20 days. Mislabeling of specimens and lack of infrastructure also delay follow-up. Many women fail to return for their results, few have phones, addresses are often hard to locate, people change residences frequently, and no door-to-door mail service exists.

\section{Fear of the procedure}

Although some women were beginning to voice the importance of Pap smears and their intention to get one, this was often delayed out of fear. In a brief survey of 60 women, $40 \%$ had had Pap smears. Of the 36 that had not had the exam, 8 stated they knew nothing about it; 10 stated that they did not feel it was necessary because they had not had symptoms; and 12 stated that they were afraid. Reasons included fear that the exam would hurt, that something bad might be found, and "that they will take something out of me".

This theme of extraction was unexpectedly continued in a conversation with a popular local curandero (healer), Brother Juan, when he was explaining various types of trauma to the vagina that he felt contributed to female cancers. These included sexual relations at a young age and "extractions that produce a serious effect". This, he explained, could be from "machines of extraction" or the apparatus that they insert into the vagina. Demonstrating on a drawing of the vagina and female organs he had made, he said, "They open this space and insert the apparatus. They grasp here and pull. So it comes out of here. The uterus comes out." Author: "Do you think that they take out the uterus with this apparatus?"

Juan: "Yes, I'll show you one so you can understand more clearly... [Juan retired momentarily to a back room and returned with a vaginal speculum, a gift from a visiting physician...] They put this in the ovary [Juan frequently mixed the terms uterus, ovary, and vagina...] The illness is inside. I will insert it completely. Then they open it". 
Research Assistant: (so fascinated that he took over the interview, leaving me completely out): "What is this used for?"

Juan: "To take out the uterus."

Research assistant: "Really? You're lying to me!"

Juan: "Then with this [the little screw] they close it. So when the uterus is here [inside the speculum] you close it. This apparatus is encroachado [closed around the uterus]."

"The apparatus has this [the screw] to manually open and close it... [He demonstrates how the uterus is captured by the speculum and pulled out through the vagina...] When it is here, you start to do its wash - when it is outside. You start to work, to cure, if it has something, a chanclo [an illness]. Then with this same apparatus, you put it back in. Once it is inside, they loosen it [the speculum], and then they close it very gently. You close it and then you can take it out very easily."

Research assistant: "Doesn't that tear the uterus?”

Juan: "It should stretch out like elastic. Once the ovary is outside, it stays in that form. A bit of the ovary comes outside. Then they tie it with a special thread."

Research assistant: "Are you explaining what doctors do?"

Juan: "Yes, like the doctors, what they do when there is cancer of the ovaries.Then,they cut, they sew, and take out the ovary."

One possibility was that Juan, and perhaps many local women, had mixed the process of a simple vaginal exam to include elements of other procedures, such as a vaginal hysterectomy, or a test for the degree of prolapsed uterus. In this confusion, a simple speculum used to promote visualization had become, in their minds, an "instrument of extraction". Other authors have also documented women's confusion regarding the purpose of vaginal exams and Pap smears 29,30,31,32. Alvarez 29 documented similar "extraction" fears among Chilean women. In a survey of 299 women, $14 \%$ expressed fear that a piece of the uterus would be extracted during a Pap test. Alvarez hypothesized that the terminology "taking a sample" was mistakenly interpreted as extracting a piece of the cervix or uterus rather than just a smear of cervical mucus.

However, it is also possible that what seemed to be a chaotic local interpretation of a vaginal exam and Pap smear was not based on confusion, but on reality. The more ominous possibility is that the women's theme that "something will be taken out" represents a fear of human rights abuses and the "collective memory of women's experiences of uninformed or co- erced sterilization" 33 (p. 221). Consider events in Peru's recent history:

"Determined to improve Peru's socioeconomic 'development', the Fujimori government launched an aggressive family planning campaign in 1995. In light of high fertility rates and high levels of maternal and child mortality in rural Andean and Amazonian communities, the Peruvian Ministry of Health imposed stringent numerical requirements on medical providers serving those communities, with an emphasis on terminal contraceptive methods. One strategy devised for complying with the quotas in rural areas were monthly 'fairs' offering a host of health care services, including tubal ligations and vasectomies. These fairs became notorious for coercive service delivery, substandard surgical procedures, and a lack of postoperative supervision. By mid-1998, in response to national and international pressure from reproductive and human rights organizations, the Ministry of Health explicitly prohibited the fairs, formally renounced its policy of numerical quotas, and instituted a series of reforms designed to ensure informed consent, quality of care, and provision of information" 33 (p. 220-221).

Considering the timing of the initiation of cervical cancer screening (1996-1997) and the number of Pap smears that had been performed during "fairs" (campañas de salud) in the first year of the program, one must speculate whether the cervical cancer screening program was not part of, or a cover for, sterilization of poor women. Interestingly, the women in both case studies who were undergoing screening and diagnostic processes also had sterilization procedures during that time. By 1998, when the country needed to clean up the image of women's health care and reproductive rights, continuing cervical screening would look good to a developed world that considered Pap smears to be a basic aspect of that care. As Boyd 34 (p. 3) pointed out, in Fujimori style, the effort could be shown off and "scripted to receive maximum public relations points."

\section{Recommendations}

Efforts are being made to explore alternatives for simplifying screening and treatment in underdeveloped countries, making them more available to more women. Possibilities include: (1) offering Pap smears on a less frequent basis 5,35 ; (2) bringing screening to remote populations 36; (3) using a simpler type of screening, such as visual inspection of the cervix after application of a dilute acetic acid (VIA) 8,37 ; (4) 
utilizing treatment methods more appropriate to underdeveloped regions, such as LEEP (loop electrosurgical excision procedure) and cryotherapy, which are fast, simple, effective, low-risk, and low-cost; and (5) reducing the visits necessary for screening and treatment of cervical abnormalities through a one or two-visit "see and treat" strategy 8,38,39; These strategies and others are considered in terms of relevancy for the Iquitos region in the following sections.

\section{Community education}

All interventions will be for naught without a widespread campaign to refocus educational efforts on screening to find precancerous changes prior to symptoms. Teaching women signs and symptoms of cervical cancer as signals to get a Pap smear or other screening procedure must be abandoned. In a resource-poor environment, individuals define themselves as "sick" at a more extreme point on a health-illness continuum, and symptoms are often quite severe before women turn for help 40. If cervical cancer is to be prevented through treatment of precancerous lesions, regular, asymptomatic screening (of whatever type) must be promoted effectively.

Public education regarding the screening procedure could most effectively be provided by a group of trained, local lay women. These women would have had exams themselves, could show other women a speculum, let them hold it, explain what it does and does not do, and could accompany women to the exam for moral support if desired. There are many women in Iquitos who would enjoy the chance to do something for their community, to use their education and to receive more, and to feel a sense of personal accomplishment. Much of the local knowledge in Iquitos is passed from woman to woman through family or neighborhood connections. This network can make or break health efforts.

\section{Screening frequency and age}

Although decreasing the frequency of Pap smears is logical for cost containment, this logic does not apply to general health exams for women, including a vaginal exam (with VIA) and health education. A prudent recommendation for this region is for a "once a year exam in the month of your birthday, starting at age sixteen", with or without admitted sexual activity. The rationale for recommending annual exams relates to the local sense of timeliness. In Iquitos, delay, personal schedule changes, and procrastination are part of daily life. A recommendation of every year may get a response of every three, if it gets a response at all.

The recommendation for early-age screening, beginning at age 16, differs from recommendations to target women ages 35 to 50 years as the highest risk group. In this region, advanced cervical cancer presents in some women in their 20s. Women in this region often initiate sexual relations very early in life, are exposed to human papillomavirus (HPV) early, and have other frequent gynecological disorders as well. Among the poor in this region, environment and poverty pose constant challenges to women's immune systems, hypothetically leaving them more susceptible to the development of cervical cancer from HPV infections 41,42. Frequent screening of younger women offers the best chance of finding and treating precancerous lesions. By age 35 to 45 , many of the women who develop cervical cancer in this region will be dead.

To reach the other end of the age spectrum, however, promotion of annual exams could include a "Traiga Su Mama" (Bring Your Mother) campaign. The value on the mother in Peruvian families, the networking and support among women, and the responsibility for parental care by adult children can be utilized to reach the older population. Younger women attending family planning clinics could be encouraged not only to take care of themselves but to encourage their mothers (or somebody's mother) to do the same. Having company to face a feared procedure is an added benefit. Vaginal exams should be performed by female health providers when possible. "Women trust women more," I was told in Iquitos.

\section{Screening and treatment site}

Alternative methods of screening and early treatment could easily fit into the existing health care structure in Iquitos. Screening exams could be done, as they are now, in multiple sites, including hospitals (outpatient clinics), community health posts in Iquitos. and some river villages. They could also be included in the occasional health campaigns sponsored by the Ministry of Health or community groups.

The river villages are accustomed to occasional visits from foreign physician groups or the local health campaigns, so a mobile unit for cervical cancer screening and early treatment would not be a completely new concept. The unit in this case would need to be a waterborne vessel with sufficient space for storage and personnel, possibly an exam room or two, and a fast motor to make the most of time. The mo- 
bile unit could incorporate education, visual screening, and a one-time "see and treat" strategy for identified abnormalities. Due to unreliability of electricity and cost factors, cryotherapy would be the treatment of choice. Although there would be no tissue obtained for biopsy, the chances for a woman from rural areas to be able to pay for the biopsy or to receive and accept later follow-up and treatment are slight to none.

More complex forms of screening and treatment could be made available in Iquitos. A funded project could potentially provide all the gynecologists in the city with a working colposcope, training, and equipment for cryotherapy or LEEP. An incentive program to draw a second pathologist to the city could provide healthy competition and manpower for timely Pap and biopsy results. If such procedures are to be relied upon, however, quality assurance monitors for taking and reading the tests must be put in place and maintained to assure reliable results.

\section{A political argument for payment}

At the time of the study, Pap tests provided by the Ministry of Health's screening program were free of charge. Prevention and health promotion are considered rights of Peruvians, provided by the State, but the cost of treatment for illness falls to the individual 43 . Treatment of pre-cancerous cervical lesions, however, is considered prevention in "cancer jargon", and should be articulated as such in a political argument for government payment of this service as well.

\section{Documentation of care}

Medical records observed in hospitals and clinics were often handwritten and next to impossible to read. Individuals went from facility to facility for health care, but records were not accessible from one facility to the next. Patient accounts of medical history were often full of misinformation and misinterpretation. These factors together made it impossible for practitioners to identify the past sequence of interventions. However, individuals were accustomed to carrying identification papers and clinic cards with appointment dates. These practices could be capitalized on to devise a similar system to record dates, methods, and results of cervical exams and treatment, which could be taken by the women from visit to visit.

\section{Herbal remedies}

A final recommendation is to incorporate both scientific and local knowledge of medicinal plants in medical and continuing education (including safe preparation and dosing). Local plants have potential for (1) boosting the immune system, (2) cleansing after sexual intercourse, menstrual periods, and following treatment for pre-cancerous or early lesions, (3) treating vaginal infections through antibiotic and anti-inflammatory properties, and (4) reducing symptoms of advanced cancer through anti-inflammatory and coagulation properties.

\section{Conclusion}

From the perspective of poor women in Iquitos, to get a Pap smear is the way to find out if you have cervical cancer. It is not a routine procedure that is expected to reassure the woman It is a procedure that requires one to embody the risk of discovering an illness for which treatment could cause household economic disintegration 30,44. Why seek early identification of an illness for which you, within your economic means, can do nothing? Why endure a test that serves only to herald a disease that will ultimately kill you? 32,45 In order to make an impact on cervical cancer in Iquitos, many things must happen. The significance of the disease must be recognized despite misleading local data, and health care policy must respond. Treatment, as well as screening, must be available and affordable. Approaches to public education must help women understand and accept prevention and treatment. Finally, women must have different stories to tell to future generations. They must be stories of successful treatment of cervical lesions before they became symptomatic and cancerous; of affordable exams and treatments that were not painful; of being informed and treated with respect and gentleness; and of survival. These stories must become the new local knowledge of cervical cancer in Iquitos. 


\section{Resumo}

O câncer cérvico-uterino representa um desafio para a saúde pública na América Latina e em grande parte do mundo subdesenvolvido como um todo. Historicamente, a questão não tem sido tratada como prioridade de saúde; entretanto, nos últimos anos houve um aumento de interesse e de financiamento para enfrentar o problema. Este estudo etnográfico sobre a experiência com o câncer cérvico-uterino foi realizado em Iquitos, Peru,entre agosto de 1998 e maio de 1999. As metodologias de pesquisa incluíram: (1) observação e entrevistas domiciliares para levantar dados sobre a ocorrência na região, sobre os sistemas de saúde e a cultura local em relação ao processo da doença; (2) entrevistas sobre experiências pessoais e familiares como câncer; $e$ (3) estudos de caso de mulheres em diversas fases do câncer cérvico-uterino ou do diagnóstico. São apresentados os achados relativos ao conhecimento $e$ experiência locais quanto ao teste de Papanicolau e câncer cérvico-uterino e sobre a ineficácia de um programa recém-inaugurado para rastreamento do câncer cérvico-uterino. Os achados orientam recomendações para intervenções na região em relação a: (1) mudanças nos programas de educação em saúde; (2) freqüencia e idade para rastreamento da doença; (3) locais para rastreamento e tratamento; (4) tipo e disponibilidade de tratamento; (5) formas de pagamento ou reembolso; (6) documentação do atendimento e (7) o potencial terapêutico das ervas medicinais.

Neoplasias do Colo Uterino; Saúde da Mulher; Vigilância da População

\section{Acknowledgements}

This study was funded by a National Research Service Award from the National Institute of Nursing Research, National Institutes of Health; a Nancy Petry Grant-in-Aid for Study Abroad from the Institute of International Education; a Tinker Field Research Grant for Latin America; and a Summer Fellowship from the University of Kansas.

\section{References}

1. International Agency for Cancer Research. Globoscan, 2000: Cancer incidence, mortality and prevalence worldwide. Lyon: International Agency for Cancer Research; 2001.

2. Alleyne G. Early detection of cervical cancer. Bull Pan Am Health Organ 1996; 30:283-4.

3. Pan-American Health Organization. Health conditions in the Americas. Washington DC: World Health Organization; 1994.

4. Pan-American Health Organization. Health conditions in the Americas. Washington DC: World Health Organization; 1998.

5. Sankaranarayanan R, Budukh AM, Rajikumar R. Effective screening programmes for cervical cancer in low-and middle-income developing countries. Bull World Health Organ 2001; 79:954-62.

6. World Health Organization. Dr. G.H. Brundtland's address to the 42nd Governing Council, International Agency for Research on Cancer. http:// www.who.int/directorgeneral/speeches/2001/en glish/20010510_iarc42council.en.html (accessed 15/Mar/2002).

7. World Health Organization. Dr. G.H. Brundtland's address: Reproductive health: a health priority. http://www.who.int/director-general/speeches/ 1999/english/19990208_hague.html (accessed 15/Mar/2002).

8. Pan American Health Organization. An overview: the cervical cancer prevention and control project. http://www.paho.org/English/HCP/HCN/ ccoverview.htm (accessed 25/Mar/2002).

9. Agar M. The professional stranger. 2nd Ed. San Diego: Academic Press; 1996.

10. Emerson RM, Fretz RI, Shaw LL. Writing ethnographic fieldnotes. Chicago: University of Chicago Press; 1995.

11. Ministério de Salud de la República del Perú. Defunciones registradas, Peru: 1990-1991. Lima: Oficina de Estadística e Informática; 1991.

12. Ministério de Salud de la República del Perú. Defunciones registradas, Peru: 1994-1995. Lima: Oficina de Estadística e Informática; 1995.

13. Ministério de Salud de la República del Perú. Defunciones registradas, Peru: 1996. Lima: Oficina de Estadística e Informática; 1996.

14. Agency for Health Care Policy and Research. Evidence report/technology assessment 5 , evaluation of cervical cytology. AHCPR Publication 99E010. Silver Spring: Agency for Health Care Policy and Research; 1999.

15. Alves V, Lima M, Utagawa M, Maeda M. Programa de controle de qualidade em citologia ginecológica do Instituto Adolfo Lutz: estratégias e análise crítica dos resultados de sua implantação-piloto. AMB Rev Assoc Med Bras 1991; 37:35-42.

16. Antezana SG. Incidencia de lesiones epiteliales del cuello uterino: Estúdios retrospectivo citohistomorfológico en el Hospital Arzobispo Loayza periodo de 1982-1990. Lima: Facultad de Medicina Alberto Hurtado; 1992.

17. Lazcano-Ponce EC, Ruiz PA, Lopez-Carillo L, Najera-Aguilar P, Avila-Ceniceros R, Escandon-Romero C, et al. Validity and reproducibility of cytologic diagnosis in a sample of cervical cancer 
screening centers in Mexico. Acta Cytol 1991; 41:277-84.

18. Ruiz PA, Lazcano-Ponce EC, Torres RD, Juarez IR, Cortez IM. Diagnostic reproducibility of Pap testing in two regions of Mexico: the need for quality control mechanisms. Bull Pan Am Health Organ 1996; 30:330-8.

19. Ponten J, Adami H, Bergstrom R, Dillner J, Frieberg L, Gustafsson L, et al. Strategies for global control of cervical cancer. Int J Cancer1995;60:1-26.

20. Stjernsward J, Eddy D, Luthra U, Stanley K. Plotting a new course for cervical cancer screening in developing countries. World Health Forum 1987; 8:42-45.

21. University of Zimbabwe, JHPIEGO Cervical Cancer Project. Visual inspection with acetic acid for cervical-cancer screening: test qualities in a primary-care setting. Lancet 1999; 353:869-73.

22. World Health Organization. Cervical cancer control in developing countries: memorandum from a WHO meeting. Bull World Health Organ 1996; 74:345-51.

23. Richart RM. Screening: the next century. Cancer 1995; 76 Suppl 10:1919-27.

24. Chamberlain J. Reasons that some screening programmes fail to control cervical cancer. In: Hakama M, Miller AB, Day NE, editors. Screening for cancer of the uterine cervix. Lyon: International Agency for Research on Cancer; 1986. p. 161-8.

25. Robles S. Introduction to the special issue: timely detection of cervical cancer. Bull Pan Am Health Organ 1996; 30:285-9.

26. Ferreccio C, Gage J, Robles S, Huivin M, Arroyo R, Delgado JM, et al. Implementing visual inspection with acetic acid in the field: the challenge of standardization. http://www.paho.org/English/ $\mathrm{HCP} / \mathrm{HCN} /$ ccoverview.htm (accessed 25/Mar/ 2002).

27. Tulinius H, Geirsson G, Sigurdsson K, Day NE. Screening for cervix cancer in Iceland. In: McBrien DCH, Slater TF, editors. Cancer of the uterine cervix: biochemical and clinical aspects. Orlando: Academic Press; 1984. p. 55-76.

28. Steller MA, Schiller JT. Human papillomavirus immunology and vaccine prospects. J Natl Cancer Inst Monogr 1996; 21:125-8.

29. Alvarez SL. Knowledge and fears among Chilean women with regard to the Papanicolaou test. Bull Pan Am Health Organ 1996; 30:354-61.

30. Boonmongkon P, Pylypa J, Nichter M. Emerging fears of cervical cancer in northeast Thailand. Anthropology and Medicine 1999; 6:35-80.

31. Gregg J. Mixed blessings: cervical cancer screening in Recife, Brazil. Med Anthropol 2000; 19:4164.
32. Wood K, Jewkes R, Abrahams N. Cleansing the womb: constructions of cervical cancer screening and womb cancer among rural black women in South Africa. Soc Sci Med 1997; 45:283-92.

33. Dean B, Valdeavellano EE, McKinley M, Saul R. The Amazon People's Resources Initiative: promoting reproductive rights and community development in the Peruvian Amazon. Health Hum Rights 2000; 4:219-26.

34. Boyd S. Secrets and lies. http://www.oneworld. org/ni/issue303/sterilize.html (accessed 01/Jan/ 2001).

35. Sherlaw-Johnson C, Gallivan S, Jenkins D. Evaluating cervical cancer screening programmes for developing countries. Int J Cancer 1997; 72:210-6.

36. Swaddiwudhipong W, Chaovakiratipong C, Nguntra P, Mahasakpan P, Lerdlukanavonge P, Koonchote S. Effect of a mobile unit on changes in knowledge and use of cervical cancer screening among rural Thai women. Int J Epidemiol 1995; 24:493-8.

37. Kitchener HC, Symonds P. Detection of cervical intraepithelial neoplasia in developing countries. Lancet 1999; 353:856-7.

38. Adelwole IF, Babarinsa IA, Odeniyi GD. Cryotherapy in the management of cervical intraepithelial neoplasia in developing countries. Int J Gynecol Obstet 1998; 60:69-70.

39. Darwish A, Gadallah H. One-step management of cervical lesions. Int J Gynaecol Obstet 1998; 61: 261-7.

40. Johansson SR. The health transition: the cultural inflation of morbidity during the decline of mortality. Health Transit Ver 1991; 2:78-89.

41. Guerrero-Alva I. Modelo de estudio prevalencia de la infección por Papilomavirus Humano en una población asintomática. Acta Cancerol 1993; 3:37-41.

42. Prussia PR, Gay GH, Bruce A. Analysis of cervicovaginal smears in girls 18 years and under. West Indian Med J 2002; 51:37-9.

43. Instituto Bartolomé de las Casas-Rimac, Centro de Estudios y Publicaciones. La salud de los pobres. Signos para Los Nuevos Tiempos 1999; 2:6-7.

44. Leatherman TL. A biocultural perspective on health and household economy in southern Peru. Med Anthropol Q 1996; 10:476-95.

45. Gregg J, Curry RH. Explanatory models for cancer among African-American women at two Atlanta neighborhood health centers: the implications for a cancer screening program. Soc Sci Med 1994; 39:519-26.

Submitted on $21 /$ Oct $/ 2002$

Final version resubmitted on $9 / \mathrm{Jun} / 2003$ Approved on 7/Oct/2003 